\title{
High efficiency single-junction semitransparent perovskite solar cells
}

\author{
Cristina Roldán-Carmona, $\dagger^{\mathrm{ab}}$ Olga Malinkiewicz, $\uparrow^{\mathrm{a}}$ Rafael Betancur, ${ }^{\mathrm{c}}$ Giulia Longo, ${ }^{\mathrm{a}}$ Cristina Momblona, ${ }^{\mathrm{a}}$ \\ Franklin Jaramillo, ${ }^{\mathrm{C}}$ Luis Camacho ${ }^{\mathrm{b}}$ and Henk J. Bolink*a
}

\author{
Received (in $X X X, X X X)$ XthXXXXXXXXX 20XX, Accepted Xth XXXXXXXXX 20XX \\ DOI: $10.1039 / b 000000 x$
}

Semitransparent perovskite solar cells with a high power 10 conversion efficiency (PCE) close to $7 \%$ and $30 \%$ full device transparency have been achieved by implementing a thin perovskite layer and a simple foil compatible layout.

Thin film photovoltaics have attracted much attention as a promising source of renewable energy to reduce the dependencies 15 on fossil and nuclear industries. ${ }^{1}$ In the past years, a lot of effort has been devoted to the development of organic photovoltaics (OPV), including new materials and device strcutures, to provide an alternative to Si-based solar cells. The advantages of OPV include their potential low cost manufacturing, light weight, 20 flexibility and the availability of different materials allowing for colour tuning of the devices. ${ }^{2-4}$ Additionally, they can be made semitransparent which allows for specific building integrated elements that could lead to totally self-sustaining buildings at low cost. Even though some breakthroughs in device efficiency has 25 been recently reported, the efficiency of single junction OPV devices is generally below $10 \% .^{5-8}$ For semitransparent (ST) solar cells, the use of absorbers with a lower bandgap, in order to shift the absorbtion spectra to the infrared region, the absence of the light reflecting electrode and the implementation of thin 30 active layers compromise even more the power conversion efficiency (PCE). ${ }^{9-12}$ In order to enhance the performance of ST solar cells, in terms of their average visible transparency (AVT) and PCE, several strategies have been implemented including extensive studies about semitransparent electrodes, tandem 35 devices and recently the implementation of more efficient materials. For the case of the transparent electrodes, the most explored material has been thin silver, ${ }^{8,13} 14$ also in combination with different capping layers, ${ }^{15-17}$ or in configurations like $\mathrm{Ag}$ grids ${ }^{18,19}$ or Ag NWs. ${ }^{12,}{ }^{20}$ PEDOT has also been explored as 40 transparent electrode. ${ }^{21,} 22$ Finally, other materials like thin $\mathrm{Al},{ }^{23}$, ${ }^{24}$ thin $\mathrm{Au}^{25,26} \mathrm{ITO}^{27,}{ }^{28}$, graphene ${ }^{29,30}$ and $\mathrm{CNT}^{31-33}$ have also been tested with more discrete results. From these studies, considering just single junction devices with AVT higher than $20 \%$, the top performance was set by Chen et al. ${ }^{8} 6.2 \%$ PCE ${ }_{45} 21.2 \%$ AVT using a thin silver layer, followed by $5.6 \%$ PCE $\sim 30 \%$ AVT ${ }^{11}$ using thin silver and including an external photonic structure for trapping the UV and NIR sunlight and finally $4.0 \%$ PCE - 50\% $\mathrm{AVT}^{12}$ using ITO nanoparticles and Ag NW mixed electrode. A way to increase the performance of this kind of ${ }_{50}$ devices has been the development of tandem OPVs, for example Chen et. al, obtained a $7 \%$ PCE - 30\% AVT. ${ }^{34}$ However, the complexity of tandem devices impedes their facile integration in low cost application easier to achieve with single junction devices with improved performances.

${ }_{55} \mathrm{An}$ alternative approach to increase the performance of semitransparent photovoltaic devices is to use more efficient materials. Methylammonium lead halide perovskites are an interesting class of materials that have excellent semiconductor properties and have led to very efficient solar cells. ${ }^{35,}{ }^{36}$ From the 60 first report by Miyasaki et al., ${ }^{37}$ tremendous progress in the performance of methylammonium lead iodide perovskite based solar cells has been achieved. ${ }^{38-43}$ Power conversion efficiencies in excess of $15 \%$ have been obtained. ${ }^{38-40}$ Most of the high efficient perovskite solar cells reported until now sandwich the 65 perovskite in between a metal oxide layer such as $\mathrm{Al}_{2} \mathrm{O}_{3}, \mathrm{TiO}_{2}$ or $\mathrm{ZrO}_{2}$, and an organic hole transport material. In most cases the organic hole-trasporting material (frequently spiro-OMeTAD) is applied on top of the perovskite as a rather thick layer and partially oxidized. The presence of the several hundred nanometer 70 thick partially oxidized hole transport layer leads to parasitic absorbtion losses reducing the transparency of the active stack. As a consequence this would ultimately limit the achievable transparency of semi-transparent devices. Based on this approach, ST perovskite solar cells achieved 3.5\% PCE $-\sim 30 \%$ AVT. ${ }^{44}$ 75 Their strategy relied on the dewetting of the perovskite film to create 'perovskite islands' achieving with this a high tranmittance but clearly decreasing the overall PCE after the present voids in the active layer.

Recently, an altenative device layout where the thickness of 80 continous perovskite layers can be precisely controlled by thermal evaporation while avoiding the use of materials that induce parasitic absoption was developed. ${ }^{45}$ In this layout the conductive polymer poly $(3,4-$ ethylenedioxythiophene):poly(styrenesulfonic acid) ${ }_{85}$ (PEDOT:PSS) is deposited on top of the transparent conductive substrate. PEDOT:PSS has been designed for its transparency in the visible part of the spectrum and with layer thicknesses around $100 \mathrm{~nm}$ has a transmittance above $90 \%$. In the first examples the perovskite layer was deposited on top of the PEDOT:PSS and 90 capped with a hole blocking/electron transporting layer ([6,6]phenyl $\mathrm{C}_{61}$-butyric acid methylester, PCBM 60 leading to PCEs of $7.4 \%$. Recenlty, You et al., improved the performance of this configuration reaching a maximum PCE of $11.5 \%{ }^{46}$ When besides the hole blocking layer also a thin electron blocking layer ${ }_{95}$ is used in between the PEDOT:PSS and the perovskite layer, the device performance is further improved to reach a PCE of 14.8 $\%{ }^{45,47}$ Hence, the transmittance of this type of solar cell is almost completely determined by the perovskite layer and the two electrodes. An additional advantage of this layout is the absence 100 of metal oxides which facilitates the manufacturing of the cells and make them compatible with flexible applications and roll to roll (R2R) processing. ${ }^{46,48}$

Here we present the development of perovskite semitransparent solar cells reaching 6.4\% PCE - 29\% AVT and 7.3\% PCE - 22\% ${ }_{105}$ AVT. This successful implementation is based on the robustness of the perovskite evaporation process enabling depositing 
continous layers as thin as $40 \mathrm{~nm}$. The strategy included the implementation of the device layout above described with minimized parasitic absorption and the development of an ultrathin gold electrode capped with a LiF layer. Such capping layer 5 was intended to protect the gold layer while simultaneously reducing the energy lost, by device specular reflection, which translated in an enhanced device transparency. These results are the best reported to date for semitransparent single junction solar cells, demonstrating their capability for building integrated 10 photovoltaics and other industrial semitransparent applications.
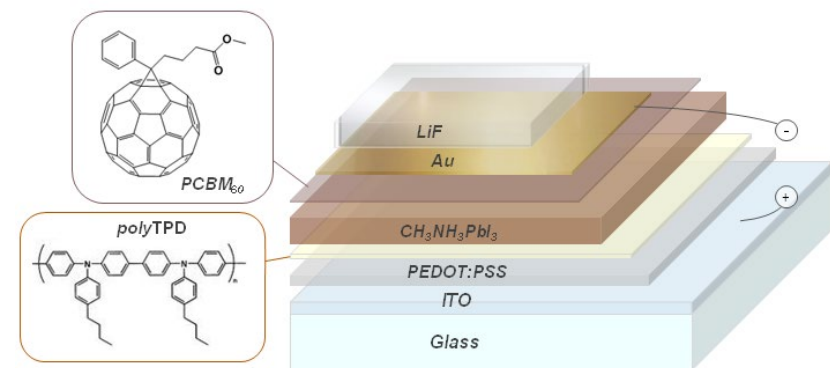

Fig. 1 Schematic layout of the semitransparent solar cell and chemical structures of the organic hole and electron blocking materials.

The architecture for the semitransparent perovskite device explored in this work is presented in Figure 1. In order to achieve a semitransparent device, the top gold electrode was only $6 \mathrm{~nm}$ thick. This structure was computationally modelled by employing 20 the transfer matrix formalism ${ }^{49,50}$ where the optical properties of the materials were obtained from literature or estimated using the method reported by Manifacier et al. ${ }^{51}$ Figure $2 \mathrm{a}$ shows the dependence of the $\mathrm{J}_{\mathrm{sc}}$ and AVT with the perovskite thickness with and without including a protective LiF layer. Clearly, a higher $\mathrm{J}_{\mathrm{sc}}$

25 is theoretically expected for thicker perovskite layers but implying a strongly reduced AVT. Therefore, a trade off needs to be achieved between its inversely related efficiency and sunlight transmission which implies the sacrificing in either efficiency or transparency as seen in recent related publications. ${ }^{44}$. This 30 negative relationship can be partially overcome by exploring optical interference effects inherent to the coherent interaction of sunlight with thin film photovoltaic devices. ${ }^{52}$ In particular, the $\mathrm{LiF}$ transparent capping layer besides providing a protection for the underlying gold layer can be used to modify the electric field 35 distribution inside the device. The optical properties of the different device layers determine that the average sunlight reflected out of the device (ARF) is minimized for the combinations of perovskite and LiF thicknesses enclosed in the white square shown in Figure 2b. Equivalent maps were 40 developed for the expected AVT and $\mathrm{J}_{\mathrm{sc}}$ (Figures $2 \mathrm{c}$ and $2 \mathrm{~d}$, respectively). From these graphs it was concluded that, for any given thickness of the perovskite layer, a LiF layer around 100 $\mathrm{nm}$ thick was optimal for reducing the energy lost by the specular reflection of the device while enabling more transparent and ${ }_{45}$ keeping a high $\mathrm{J}_{\mathrm{sc}}$ as shown in Fig $2 \mathrm{a}$ (dashed lines). a)

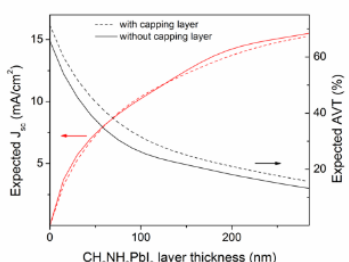

c)

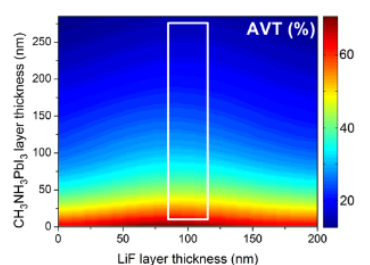

d)
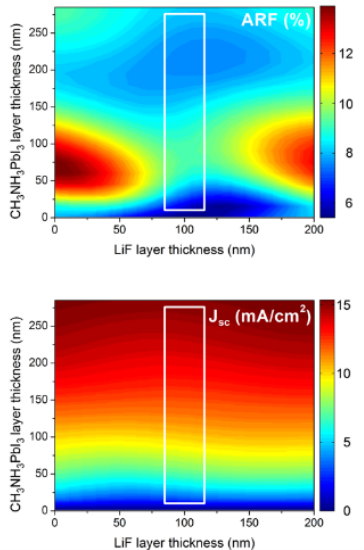

Fig.2. Optical modelling of the semitransparent perovskite solar cells. a) 50 Negative-related $J_{\text {sc }}$ (red lines) and AVT (black lines) for a $6 \mathrm{~nm}$ thick gold device. The effect of including a $100 \mathrm{~nm} \mathrm{LiF}$ capping layer is illustrated (dashed lines). In general, such capping layer modifies the field distribution inside the device and which has an effect on the (b) average reflected sunlight (ARF, $400-800 \mathrm{~nm}$ ), (c) average visible transmission 55 (AVT, 400-800 nm) and (d) short-circuit current density. The white square encloses the combinations of $\mathrm{CH}_{3} \mathrm{NH}_{3} \mathrm{PbI}_{3}$ and $\mathrm{LiF}$ thicknesses that simultaneously reduce the ARF, enhance the AVT and keep a high $\mathrm{J}_{\mathrm{sc}}$.

The semitransparent solar cells were prepared by sandwiching the 60 methylammonium lead iodide perovskite between two very thin electron and hole-blocking layers consisting of organic molecules (see Figure 1). First, a $75 \mathrm{~nm}$ of poly (3,4ethylenedioxythiophene):poly(styrenesulfonic acid) (PEDOT:PSS) CLEVIOS P VP Al 4083 from Hereaus was spin65 coated on an ITO covered glass substrate. After annealing for 15 minutes at $150{ }^{\circ} \mathrm{C}$, a thin layer of the electron-blocking material poly[N,N'-bis(4-butylphenyl)-N,N'-bis(phenyl)benzidine]

(polyTPD) from ADSdyesource was deposited $(20 \mathrm{~nm})$ from a chlorobenzene solution $\left(7 \mathrm{mg} \mathrm{ml}^{-1}\right)$ and then annealed at $180{ }^{\circ} \mathrm{C}$ 70 during 30 minutes. This annealing step was required in order to fix the polyTPD and prevent its removal when the hole-blocking layer is deposited on the rather thin perovskite layers from the same solvent. To ensure a high purity and a high control of the thickness, the $\mathrm{CH}_{3} \mathrm{NH}_{3} \mathrm{PbI}_{3}$ layers were prepared by the co75 evaporation of the two starting materials $\mathrm{PbI}_{2}$ and $\mathrm{CH}_{3} \mathrm{NH}_{3} \mathrm{I}$ in a high vacuum chamber as described previously ${ }^{45,48}$. Four different thicknesses $(40 \mathrm{~nm}, 100 \mathrm{~nm}, 180 \mathrm{~nm}$ and $280 \mathrm{~nm})$ were evaluated. Subsequently, a thin layer $(20 \mathrm{~nm})$ of the hole-blocking material $[6,6]$-phenyl $\mathrm{C}_{61}$-butyric acid methylester $\left(\mathrm{PCBM}_{60}\right)$ Solenne BV 80 was deposited from a chlorobenzene solution, $10 \mathrm{mg} \mathrm{ml}^{-1}$, using meniscus coating. ${ }^{53}$ The thickness of the layers was verified using both perfilometer and absorbance measurements. For nontransparent devices the described stack was covered by an $70 \mathrm{~nm}$ gold layer deposited using vacuum evaporation. In the case of ${ }_{85}$ semitransparent devices an alternative top electrode is required that is conductive and has a high transparency. Additionally, the top electrode and its deposition method should be compatible with the device stack. Therefore, only top electrodes prepared by evaporation of metals and dielectrics were considered (Figure ${ }_{90} \mathrm{~S} 1$ ). The optimum gold layer had a thickness of $6 \mathrm{~nm}$, as it showed good homogeneity, acceptable conductivity and transparency values. This gold layer is considerably thinner than previously reported semitransparent gold layers in ST perovskite devices ${ }^{44}$ which leads to a reduction on the parasitic absorption 95 always induced by metallic layers. As predicted by the optical model, this ultra-thin layer of Au $(6 \mathrm{~nm})$ was capped by a $100 \mathrm{~nm}$ layer of lithium fluoride $(\mathrm{LiF})$ to enhance optically the device. 
This LiF layer also protected the cell allowing for easier handling. More details of the device fabrication and characterization are provided in the ESI. $\dagger$

5 The robustness of the thermal evaporation to grow perovskite layers in a wide range of thicknesses is crucial to the development of these semitransparent perovskite solar cells. Indeed, the resulting $\mathrm{CH}_{3} \mathrm{NH}_{3} \mathrm{PbI}_{3}$ layers showed a very high crystallinity and uniformity as evidenced by grazing incidence $\mathrm{X}$ 10 ray diffraction (GIXRD) and Scanning Electron Microscopy. As shown in Figure 3a, despite their thicknesses, all the deposited perovskite layers showed a high crystallinity reaching an excellent fit to a one-phase model with a tetragonal cell $(a=$ $8.80(2), c=12.57(2) \AA$ ) and space group $14 / \mathrm{cm}$. Additionally, a 15 high film uniformity is apparent from the SEM pictures presented in Figure 3b.

a)

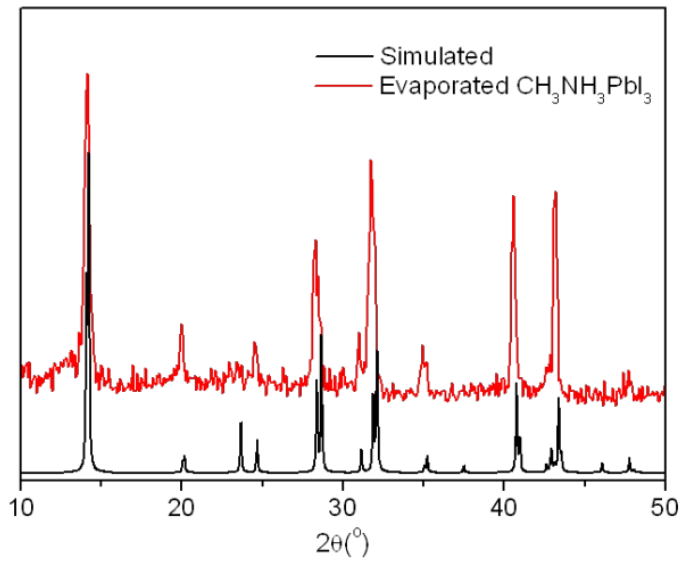

b)

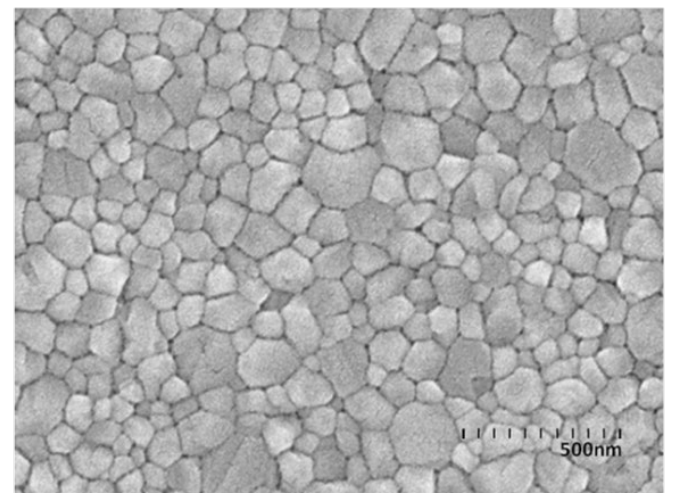

Fig. 3. (a) Grazing incidence X-ray diffraction (GIXRD) pattern of a typical evaporated $\mathrm{CH}_{3} \mathrm{NH}_{3} \mathrm{PbI}_{3}$ film. As reference, it is also added the simulated perovskite pattern with preferred orientation along the (100) and (001) directions. (b) SEM picture of a typical evaporated perovskite layer of $200 \mathrm{~nm}$.

The transmittance of the layers including the glass substrate (device without top electrode), the ST top contact and the 20 completed ST device are depicted in Figure S2 for a perovskite thickness of $100 \mathrm{~nm}$. Clearly, the ST top electrode reduces significantly the transmittance of the complete device. The transmittance spectra for the completed ST device employing different perovskite layer thicknesses are shown in Figure 4a. As

25 expected the transmission increases with reducing perovskite layer thickness, although not completely linearly in function of the film thickness probably due to slight changes in the perovskite optical properties depending on its particular evaporation process. To highlight the effect of the different 30 perovskite thickness on the transparency of the device, the values for the AVT of the device stacks with and without the ST top electrode are given (inset Figure 4a). Such AVT is taken as the average of the transmittance in the visible region of the spectra between $400-800 \mathrm{~nm}$. The stack layout (without top electrode) 35 leads to good transmittances when the thickness is below $200 \mathrm{~nm}$, showing an AVT of $44 \%$ for a perovskite thickness of $100 \mathrm{~nm}$. Thicker perovskite films lead to an important decrease in the transmittance, reducing the AVT value to $19 \%$ for films with a thickness of $280 \mathrm{~nm}$.

The completed device with a perovskite layer thickness of 100 $\mathrm{nm}$ has an AVT close to $30 \%$ which is high enough for many applications. Figure $4 \mathrm{c}$ shows the current density versus voltage $(J-V)$ characteristics for the described cells with $0.12 \mathrm{~cm}^{2}$ active 45 area under light intensities of $100 \mathrm{~mW} \mathrm{~cm}^{-2}$. It is important to mention that the curves are the same under forward and reverse scan directions and as such do not display hysterises.
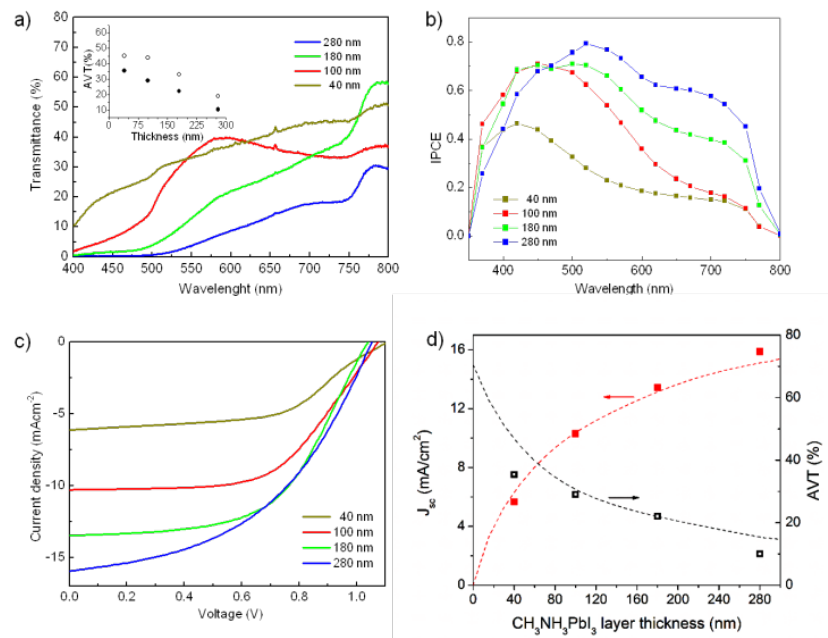

50 Fig. 4. a) Transmittance spectra through the complete device for different perovskite layer thicknesses. The inset shows the AVT values for the devices with the ST electrode (filled circle) and without (open circles). b) IPCE spectrum and c) $\mathrm{J}-\mathrm{V}$ characteristics of the best semitransparent devices comprising the $\mathrm{Au} / \mathrm{LiF}$ electrode for different perovskite 55 thicknesses. d) Comparison between the experimentally obtained AVT (red full squares) and $\mathrm{J}_{\mathrm{sc}}$ (black empty squares) with the optical modelling (dashed lines).

The results show a decrease of the current density when the 60 active layer thickness decreases. This is expected as less light is absorbed and as a consequence fewer charges can be photogenerated. This trend is also seen in the IPCE graph (Figure 4b) where the most notable decrease is observed in the red region of the spectra. The key performance parameter deduced from Figure ${ }_{65} 4$ for the different devices are depicted in Table 1. Additionally, an informative table including average values and standard deviation for the most important parameters can be found in the supporting information, Table S2.

70 Finally, Figure 4d presents a comparison between the experimentally obtained parameters and the optically modelled ones. A reasonably good fitting was achieved. Just small 
discrepancies appeared for the AVT in the case of the 40 and 280 $\mathrm{nm}$ thick perovskite devices which could be due to slight changes in their thicknesses or the before-mentioned small variations in the optical properties of the deposited perovskite layers. All ${ }_{5}$ devices exhibited a yellowish/brown tonality with considerably good agreement with the optical modelling (Figure S3). The 40 $\mathrm{nm}$ thick perovskite device displayed the most neutral color $(0.36 ; 0.37)$ and future works could be addressed to develop optical strategies to tune such tonalities.

10 During the optical computer simulation the IPCE was modelled as IPCE $=\phi \eta_{a b s}(\lambda){ }^{50}$ where $\eta_{a b s}(\lambda)$ is related to the efficiency in absorbing the sunlight and the wavelengthindependent parameter $\phi$ is associated to the exciton diffusion efficiency, charge separation efficiency, charge transport 15 efficiency and final charge collection efficiency. The final fiting of this $\phi$ parameter, after matching the experimental and computer modelled $J_{\mathrm{sc}}$, resulted to be 0.9 which evidences the excellent exciton and charge conductivity properties of the perovskite layers.

Table 1. Most important parameters for the best studied semitransparent solar cells.

\begin{tabular}{c|cccccc}
\hline & $\begin{array}{c}J \mathbf{s c} \\
(\mathbf{m A ~ c m}\end{array}$ & $\begin{array}{c}\text { Voc } \\
(\mathbf{V})\end{array}$ & $\mathbf{F F}$ & $\begin{array}{c}\text { PCE } \\
(\%)\end{array}$ & $\begin{array}{c}\mathbf{A V T}^{\mathbf{1}} \\
(\mathbf{\%})\end{array}$ & $\begin{array}{c}\mathbf{A V T}^{\mathbf{2}} \\
(\mathbf{\%})\end{array}$ \\
\hline $\mathbf{4 0} \mathbf{~ n m}$ & 5.66 & 1.037 & 57.7 & 3.39 & 35.4 & 45 \\
\hline $\mathbf{1 0 0 n m}$ & 10.30 & 1.074 & 57.9 & 6.41 & 29 & 44 \\
\hline $\mathbf{1 8 0 n m}$ & 13.43 & 1.037 & 52.5 & 7.31 & 22 & 33 \\
\hline $\mathbf{2 8 0 n m}$ & 15.88 & 1.052 & 46. & 7.73 & 10 & 19
\end{tabular}

${ }^{1}$ Average transmittance values through the whole device

${ }^{2}$ Average transmittance values without the top semitransparent electrode

As a result power conversion efficiencies as high as $6.4 \%$ for devices with an AVT of $30 \%$ were achieved. This is amongst the highest values reported for semitransparent single-junction cells. Most of the devices lead to quite high short-circuit current 30 densities $\left(J_{\mathrm{sc}}\right)\left(10\right.$ to $\left.16 \mathrm{~mA} \mathrm{~cm}{ }^{-2}\right)$. The $V_{\text {oc }}$ is almost not affected by the thickness of the active layer and remains above $1 \mathrm{~V}$ in all the cells. The fill factor (FF) is good for the thin devices, reaching values of $60 \%$, yet with increasing perovskite layer thickness it decreases to around $45 \%$. The reduction of the FF of the cells 35 with thicker perovskite layers is likely caused by the limited conductivity of the ST top electrode. Comparison experiments were performed with the same perovskite layer yet with a thicker $(70 \mathrm{~nm})$ top electrode and these non-transparent devices had slightly higher current densities and FF around $60 \%$ (see Table ${ }_{40} \mathrm{~S} 2$ of the ESI).

The obtained $100 \mathrm{~nm}$ or $180 \mathrm{~nm}$ perovskite cells represent one of the best performances reported for semitransparent singlejunction solar cells achieving power conversion efficiencies as ${ }_{45}$ high as $6.4 \%$ and $7.3 \%$ respectively. A photograph of a typical semitransparent solar cell is shown in Fig.5. Typical samples look yellowish/light brown, depending on the perovskite thickness (see SI, Figure S3). More importantly, this work shows a clear route to develop high performance ST solar cells.

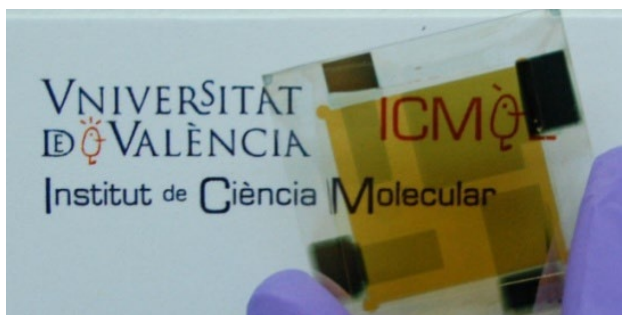

Fig. 5 Photograph of the semitransparent solar cell having a $100 \mathrm{~nm}$ perovskite layer resulting in an AVT 30\% and a PCE of $6.4 \%$. 55

\section{Conclusions}

We have successfully prepared high efficient semitransparent 60 solar cells based on methylamonium lead iodide perovskite layers sandwiched in between two organic charge transport layers. A simple cell configuration, which does not require high temperature processes, leads to semitransparent cells with AVT close to $22 \%$ and $29 \%$ through the complete device, and high 65 power conversion efficiencies of $7.3 \%$ and $6.4 \%$ respectively. These results are among the best performances reported to date for single ST solar cells and are fundamentally based on the successful development of thin uniform perovskite layers by thermal evaporation. Additionally, the implementation of a ultra70 thin gold layer as electrode enabled minimizing its parasitic absorption and, the introduction of a $\mathrm{LiF}$ capping layer was crucial to reduce the energy lost in the device specular reflection enhancing the device transparency without affecting the photon harvesting in the active layer. Furthermore, better performances 75 are expected by implementing these ideas with even better semitransparent electrodes.

\section{Acknowledgements}

${ }_{80} \mathrm{We}$ are grateful to Jorge Ferrando and Alejandra Soriano for technical assistance. This work has been supported by the Spanish Ministry of Economy and Competitiveness (MINECO) (MAT2011-24594), the GeneralitatValenciana (Prometeo/2012/053). C.R.-C. would like to thank the MINECO ${ }_{85}$ for the financial support of this research in the framework of project CTQ2010-17481, the Junta de Andalucía (CICyE) for special financial support (P10-FQM-6703) and the MECD (Spanish Ministry ofEducation, Culture, and Sport) for a FPU grant. F.J. and R.B. thank the program "Estrategia de ${ }_{90}$ Sostenibilidad 2013-2014 de la Universidad de Antioquia" and Empresas Públicas de Medellin-EPM for funding the optical simulation of the project. Additionally, F.J. and R.B. thank Jordi Martorell for useful guidance in the development of the optical modeling of the photovoltaic devices.

9

\section{Notes and references}

+ These authors contributed equally to this work.

$100{ }^{a}$ Instituto de Ciencia Molecular, Universidad de Valencia, C/Catedrático J. Beltrán 2,46980 Paterna, Valencia,Spain.E-mail: henk.bolink@uv.es

${ }^{b}$ Department of Physical Chemistry and Applied Thermodynamics,

University of Cordoba, Campus Rabanales, Ed. C3, 14014, Spain

${ }^{c}$ Centro de investigación, innovación y desarrollo de materiales-

105 CIDEMAT, Universidad de Antioquia UdeA, Calle 70 No 52-21,

Medellin, Colombia 
$\dagger$ Electronic Supplementary Information (ESI) available:Experimental details on device preparation and characterization, electrode transmittance measurements, comparison cells with thick electrodes, transmission spectra and chromaticity coordinates. See

${ }_{5}$ DOI: $10.1039 / b 000000 x$ /

1A. Name, B. Name and C. Name, Journal Title, 2000, 35, 3523; A. Name, B. Name and C. Name, Journal Title, 2000, 35, 3523. Nature, 2012, 485, 486-489.

3. G. Li, R. Zhu and Y. Yang, Nat Photon, 2012, 6, 153-162

4. J. You, L. Dou, K. Yoshimura, T. Kato, K. Ohya, T. Moriarty,

15 K. Emery, C.-C. Chen, J. Gao, G. Li and Y. Yang, Nat Commun, 2013, 4

5. Z. He, C. Zhong, S. Su, M. Xu, H. Wu and Y. Cao, Nat Photon, 2012, 6, 591-595.

$6 . \quad$ D.-D. Zhang, X.-C. Jiang, R. Wang, H.-J. Xie, G.-F. Ma, Q.-

20 D. Ou, Y.-L. Chen, Y.-Q. Li and J.-X. Tang, ACS Applied Materials \& Interfaces, 2013, 5, 10185-10190.

7. Z. M. Beiley, M. G. Christoforo, P. Gratia, A. R. Bowring, P. Eberspacher, G. Y. Margulis, C. Cabanetos, P. M. Beaujuge, A. Salleo and M. D. McGehee, Advanced Materials, 2013, 25, 7020-7026.

8. K.-S. Chen, J.-F. Salinas, H.-L. Yip, L. Huo, J. Hou and A. K. Y. Jen, Energy \& Environmental Science, 2012, 5, 9551-9557.

9. H. Zhang, G. Wicht, C. Gretener, M. Nage, F. Nüesch, Y. Romanyuk, Jean-NicolasTisserant and R. Hany, Solar Energy Materials \& Solar Cells, 2013, 118, 157-164.

30

10. H. P. L. Kim, H. J.; Jang, J., Solar Energy Materials \& Solar Cells, 2013, 108, 38-43.

11. R. Betancur, P. Romero-Gomez, A. Martinez-Otero, X. Elias, M. Maymo and J. Martorell, Nat Photon, 2013, 7, 995-1000.

$3512 . \quad$ C.-C. Chen, L. Dou, R. Zhu, C.-H. Chung, T.-B. Song, Y. B Zheng, S. Hawks, G. Li, P. S. Weiss and Y. Yang, ACS Nano, 2012, 6, 7185-7190.

13. R. F. Bailey-Salzman, B. P. Rand and S. R. Forrest, Applied Physics Letters, 2006, 88, 233502.

$4014 . \quad$ C.-C. Chen, L. Dou, R. Zhu, C.-H. Chung, T.-B. Song, Y. B. Zheng, S. Hawks, G. Li, P. S. Weiss and Y. Yang, ACS Nano, 2012, 6, 7185-7190.

15. Y. Galagan, M. G. Debije and P. W. M. Blom, Applied Physics Letters, 2011, 98, 043302.

$4516 . \quad$ S. Han, S. Lim, H. Kim, H. Cho and S. Yoo, IEEE Journal of Selected Topics in Quantum Electronics, 2010, 16, 1656-1664.

17. J. Meiss, F. Holzmueller, R. Gresser, K. Leo and M. Riede, Applied Physics Letters, 2011, 99, 193307.

18. T. Ameri, G. Dennler, C. Waldauf, H. Azimi, A. Seemann, K Forberich, J. Hauch, M. Scharber, K. Hingerl and C. J. Brabec, Advanced Functional Materials, 2010, 20, 1592-1598.

$19 . \quad$ A. Seemann, H. J. Egelhaaf, C. J. Brabec and J. A. Hauch, Organic Electronics, 2009, 10, 1424-1428.

$20 . \quad$ J.-Y. Lee, S. T. Connor, Y. Cui and P. Peumans, Nano Letters, 55

21. A. Colsmann, M. Reinhard, T.-H. Kwon, C. Kayser, F. Nickel, J. Czolk, U. Lemmer, N. Clark, J. Jasieniak, A. B. Holmes and D. Jones, Solar Energy Materials and Solar Cells, 2012, 98, 118-123.

6022 J. Czolk, A. Puetz, D. Kutsarov, M. Reinhard, U. Lemmer and A. Colsmann, Advanced Energy Materials, 2013, 3, 386-390.

23. A. Colsmann, A. Puetz, A. Bauer, J. Hanisch, E. Ahlswede and U. Lemmer, Advanced Energy Materials, 2011, 1, 599603.

$6524 . \quad$ A. Bauer, T. Wahl, J. Hanisch and E. Ahlswede, Applied Physics Letters, 2012, 100, 073307.

25. G. Li, C. W. Chu, V. Shrotriya, J. Huang and Y. Yang, Applied Physics Letters, 2006, 88, 253503.

26. V. Shrotriya, E. H.-E. Wu, G. Li, Y. Yao and Y. Yang, 70

27. Applied Physics Letters, 2006, 88, 064104.

Kowalsky, Applied Physics Letters, 2009, 94, 243302

28.
Z. Liu, J. Li, Z.-H. Sun, G. Tai, S.-P. Lau and F. Yan, $A C S$ Nano, 2011, 6, 810-818.

Y.-Y. Lee, K.-H. Tu, C.-C. Yu, S.-S. Li, J.-Y. Hwang, C.-C. Lin, K.-H. Chen, L.-C. Chen, H.-L. Chen and C.-W. Chen, ACS Nano, 2011, 5, 6564-6570.

S. Tanaka, A. A. Zakhidov, R. Ovalle-Robles, Y. Yoshida, I. Hiromitsu, Y. Fujita and K. Yoshino, Synthetic Metals, 2009, $159,2326-2328$

X. Xia, S. Wang, Y. Jia, Z. Bian, D. Wu, L. Zhang, A. Cao and C. Huang, Journal of Materials Chemistry, 2010, 20, 8478-8482.

Y. H. Kim, L. Müller-Meskamp, A. A. Zakhidov, C. Sachse, J. Meiss, J. Bikova, A. Cook, A. A. Zakhidov and K. Leo, Solar Energy Materials and Solar Cells, 2012, 96, 244-250.

C.-C. Chen, L. Dou, J. Gao, W.-H. Chang, G. Li and Y. Yang, Energy \& Environmental Science, 2013, 6, 2714-2720.

C. R. Kagan, D. B. Mitzi and C. D. Dimitrakopoulos, Science, 1999, 286, 945-947.

M. Kaltenbrunner, M. S. White, E. D. Głowacki, T. Sekitani, T. Someya, N. S. Sariciftci and S. Bauer, Nat Commun, 2012, 3,770 .

A. Kojima, K. Teshima, Y. Shirai and T. Miyasaka, J. Am. Chem. Soc., 2009, 131, 6050-6051. Alexander-Webber, J. Huang, M. Saliba, I. Mora-Sero, J. Bisquert, H. J. Snaith and R. J. Nicholas, Nano Lett., 2014, 14, 724-730.

D. Liu and T. L. Kelly, Nat Photon, 2014, 8, 133-138.

M. Liu, M. B. Johnston and H. J. Snaith, Nature, 2013, 501, 395-398.

J. Burschka, N. Pellet, S.-J. Moon, R. Humphry-Baker, P. Gao, M. K. Nazeeruddin and M. Gratzel, Nature, 2013, 499, 316-319.

J. M. Ball, M. M. Lee, A. Hey and H. J. Snaith, Energy \&

Environmental Science, 2013, 6, 1739-1743.
M. M. Lee, J. Teuscher, T. Miyasaka, T. N. Murakami and H. J. Snaith, Science, 2012, 338, 643-647.

G. E. Eperon, V. M. Burlakov, A. Goriely and H. J. Snaith, ACS Nano, 2014, 8, 591-598.

O. Malinkiewicz, Y. Aswani, Y. H. Lee, M. Minguez Espallargas, M. Graetzel, M. K. Nazeeruddin and H. J. Bolink, Nature Photonics, 2014, 8, 128.

J. You, Z. Hong, Y. Yang, Q. Chen, M. Cai, T.-B. Song, C.-C. Chen, S. Lu, Y. Liu and H. Zhou, Acs Nano, 2014, DOI: 10.1021/nn406020d.

O. Malinkiewicz, C. Roldán-Carmona, A. Soriano, E. Bandiello, L. Camacho, M. K. Nazeeruddin and H. J. Bolink, Adv. Ener. Mater., 2014, DOI: 10.1002/aenm.201400345, n/a$\mathrm{n} / \mathrm{a}$.

C. Roldan-Carmona, O. Malinkiewicz, A. Soriano, G. Minguez Espallargas, A. Garcia, P. Reinecke, T. Kroyer, M. I. Dar, M. K. Nazeeruddin and H. J. Bolink, Energy \& Environmental Science, 2014, 7, 994.

L. A. A. Pettersson, L. S. Roman and O. Inganas, Journal of Applied Physics, 1999, 86, 487-496.

R. Betancur, Doctoral dissertation, 2013.

J. C. Manifacier, J. Gasiot, and J. P. Fillard, Journal of Physics E: Scientific Instruments, 1976, 9, 1002

M. Niggemann, M. Riede, A. Gombert and K. Leo, physica status solidi (a), 2008, 205, 2862-2874.

O. Malinkiewicz, M. Lenes, H. Brine and H. J. Bolink, Rsc Advances, 2012, 2, 3335-3339. 


\title{
High efficiency single-junction semitransparent perovskite solar cells Supporting information
}

\begin{abstract}
Cristina Roldán-Carmona, $\uparrow^{\text {ab }}$ Olga Malinkiewicz, $\uparrow^{\dagger \mathrm{a}}$ Rafael Betancur, ${ }^{\mathrm{c}}$ Giulia Longo, ${ }^{\mathrm{a}}$ Cristina Momblona, ${ }^{\mathrm{a}}$ Franklin Jaramillo, ${ }^{\mathrm{c}}$ Luis Camacho ${ }^{\mathrm{b}}$ and Henk J. Bolink*a
\end{abstract}

$\dagger$ These authors contributed equally to this work

${ }^{a}$ Instituto de Ciencia Molecular, Universidad de Valencia, C/ Catedrático J. Beltrán 2, 46980 Paterna (Valencia), Spain. henk.bolink@uv.es

${ }^{b}$ Department of Physical Chemistry and Applied Thermodynamics, Campus Rabanales, Ed. C3, University of Cordoba, 14014, Spain.

${ }^{c}$ Centro de investigación, innovación y desarrollo de materiales-CIDEMAT, Universidad de Antioquia UdeA, Calle 70 No 52-21, Medellín, Colombia

Email: henk.bolink@uv.es

\section{Content:}

1. Methods: materials, device preparation and characterization. (Page 2)

2. Electrode transmittance measurements. (Page 2-3)

3. Perovskite film characterization. (Page 3)

4. Performance of perovskite solar cells with $70 \mathrm{~nm}$ Au as cathode. (Page 4)

5. Transmittance spectra for optimized device. (Page 4)

6. Chromaticity coordinates for the semitransparent devices (Page 4) 


\section{Methods}

\section{Materials}

Aqueous dispersions of poly(3,4-ethylenedioxythiophene) doped with poly(styrenesulfonate) (PEDOT:PSS, CLEVIOS P VP Al 4083) were obtained from Heraeus Holding GmbH and used as received. Poly[N,N'-bis(4butylphenyl)-N,N'-bis(phenyl)benzidine] (poly-TPD) was purchased from ADS Dyesource. $\mathrm{PbI}_{2}$ was purchased from Aldrich and used as is, $\mathrm{CH}_{3} \mathrm{NH}_{3} \mathrm{I}$ was prepared similar to a previously published method ${ }^{1}$, in brief: $\mathrm{CH}_{3} \mathrm{NH}_{3} \mathrm{I}$, was synthesized by reacting $21.6 \mathrm{ml}$ methylamine (40\%wt in water, Aldrich) and $30 \mathrm{ml}$ hydroiodic acid (57 wt\% in water,Aldrich) in a $250 \mathrm{ml}$ round-bottomed flask at $0{ }^{\circ} \mathrm{C}$ for $2 \mathrm{~h}$ with stirring. The white precipitate was recovered by evaporation at $50{ }^{\circ} \mathrm{C}$ for $1 \mathrm{~h}$. The product, methylammonium iodide $\left(\mathrm{CH}_{3} \mathrm{NH}_{3} \mathrm{I}\right)$, was dissolved in ethanol, filtered and recrystallized from diethyl ether, and dried at $60{ }^{\circ} \mathrm{C}$ in a vacuum oven for $24 \mathrm{~h}$.

\section{Device preparation}

Devices were prepared on a photolithographically patterned ITO on glass substrates, by spincoating a thin layer of PEDOT:PSS from the commercial aqueous dispersion (1000rpm 30sec and a short annealing at $150{ }^{\circ} \mathrm{C}$ result in $75 \mathrm{~nm}$ thickness). On top of this layer a thin film of polyTPD was deposited from a chlorobenzene solution (7 $\mathrm{mg} \mathrm{ml}^{-1}$ ) using spincoating. Then the substrates were annealed at $180{ }^{\circ} \mathrm{C}$ during 30 minutes and transferred to a vacuum chamber integrated into an inert glovebox (MBraun, $<0.1 \mathrm{ppm}_{2}$ and $<0.1 \mathrm{ppm}_{2} \mathrm{O}$ ) and evacuated to a pressure of $1 \times 10^{-6}$ mbar. The sublimation of the perovskite was performed using a vacuum chamber of MBraun integrated in an inert glovebox (MBraun) as previously reported ${ }^{2}$. The PCBM 60 layer was deposited using a chlorobenzene solution of $10 \mathrm{mg} \mathrm{ml}^{-1}$ in ambient conditions using a meniscus coater and a coating speed of $10 \mathrm{~mm} /$ second. The device was completed by the thermal evaporation of the top semitransparent electrode under a base pressure of $2 \times 10^{-6}$ mbar. The solar cells (active area of $0.12 \mathrm{~cm}^{2}$ ) were characterized inside the inert glovebox.

\section{Device characterization}

Solar cells were illuminated by a white light halogen lamp in combination with interference filters for the EQE and $J-V$ measurements (MiniSun simulator by ECN the Netherlands). A black mask with openings matching the active cell area was used to limit the active area of the device. Before each measurement, the exact light intensity was determined using a calibrated Si reference diode. An estimation of the short-circuit current density $\left(J_{\mathrm{sc}}\right)$ under standard test conditions was calculated by convolving the EQE spectrum with the AM1.5G reference spectrum, using the premise of a linear dependence of $J_{\text {sc }}$ on light intensity. Current-voltage $(J-V)$ characteristics were measured using a Keithley 2400 source measure unit. All characterization was done in a nitrogen filled glove box $\left(<0.1 \mathrm{ppm}_{2}\right.$ and $\left.<0.1 \mathrm{ppm}_{2} \mathrm{O}\right)$ without exposure to ambient atmosphere. 


\section{Electrode transmittance measurements}

Different cathodes were prepared in order to use the most appropriate to our cell configuration. All of them consisted on an evaporated mixture of metals, metals and oxides, as well as the lithium fluoride salt. Due to the better performance of our solar cells when using gold as the cathode, it was used as the seed layer in most of the cases. The transmittance of the studied cathodes is shown in Figure S1.

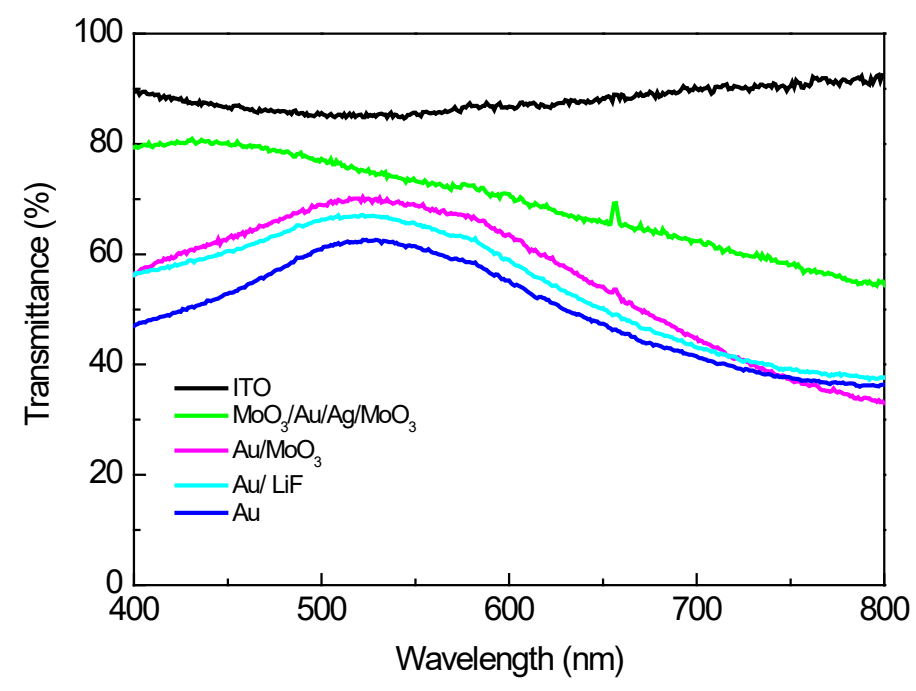

Figure S1. Transmittance spectra for the different semitransparent electrodes. The presence of $\mathrm{LiF}$ and $\mathrm{MoO}_{3}$ increases slightly the transmittance referred to the $6 \mathrm{~nm}$ gold. ITO electrode is also included as a reference.

Table S1. Most important parameters of non optimized semitransparent solar cells with the following configuration: ITO/PEDOT:PSS/PolyTPD/Perovskite/PCBM $60 / \mathrm{ST}$ electrode for an active layer thickness of $250 \mathrm{~nm}$.

\begin{tabular}{|c|c|c|c|c|c|}
\hline ST electrode & 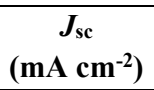 & $V_{\text {oc }}(\mathbf{V})$ & FF & PCE (\%) & $\begin{array}{c}\text { AVT }^{1} \\
(\%)\end{array}$ \\
\hline Au (6nm) & 14.0 & 1.019 & 45.8 & 6.6 & 52 \\
\hline Au (6nm)/ LiF (100nm) & 13.5 & 1.035 & 46.2 & 6.4 & 56 \\
\hline $\mathrm{Au}(6 \mathrm{~nm}) / \mathrm{MoO}_{3}(15 \mathrm{~nm})$ & 5.2 & 0.929 & 27.6 & 1.4 & 59 \\
\hline $\mathrm{MoO}_{3}(3 \mathrm{~nm}) / \mathrm{Au}(1 \mathrm{~nm}) / \mathrm{Ag}(6 \mathrm{~nm}) / \mathrm{MoO}_{3}(5 \mathrm{~nm})^{5}$ & 9.5 & 0.915 & 9.9 & 0.9 & 71 \\
\hline
\end{tabular}

${ }^{1}$ Average transmittance for the electrode.

\section{Perovskite film characterization}

\section{Grazing incidence X-ray diffraction (GIXRD)}

After the evaporation of the perovskite the films were characterized by using grazing incidence X-ray diffraction (GIXRD). The data were collected at room temperature in the $2 \theta$ range 5-50 ${ }^{\circ}$ on an Empyrean PANalytical powder diffractometer, using $\mathrm{Cu} \mathrm{K} \alpha 1$ radiation. In Figure 2a a typical difractogram for the thin perovskite layer is shown. Typically four repeated measurements were collected and merged into a single diffractogram. Pawley refinements ${ }^{3}$, were performed using the TOPAS computer program ${ }^{4}$ and revealed an excellent fit to a one-phase model with a tetragonal cell $(a=8.80(2), c=12.57(2) \AA)$ and space group $I 4 / \mathrm{cm}$.

\section{Scanning Electron Microscopy}


Perovskite film morphology was investigated using a high-resolution scanning electron microscope (MERLIN, Zeiss) and micrographs were acquired using an in-lens secondary electron detector (Figure $2 b$ ).

\section{Performance of perovskite solar cells with $70 \mathrm{~nm}$ Au as cathode}

Comparison experiments were performed with the same device structure and perovskite layer thicknesses but using a thicker $(70 \mathrm{~nm})$ top electrode. Table S2 summarizes the most important parameters of these cells.

Table S2. Key parameters of perovskite solar cells with the following configuration: ITO/PEDOT:PSS/PolyTPD/Perovskite/PCBM $60 / A_{\text {Au for }}$ different active layer thicknesses.

\begin{tabular}{|c|c|c|c|c|c|}
\hline Perovskite thickness & $\boldsymbol{J}_{\text {sc }}\left(\mathbf{m A ~ c m}^{-\mathbf{2}}\right)$ & $\boldsymbol{V}_{\mathbf{~ o c}}(\mathbf{V})$ & FF & PCE (\%) & AVT $^{\mathbf{1}}(\mathbf{\%})$ \\
\hline $\mathbf{4 0} \mathbf{~ n m}$ & 9.12 & 1.021 & 47.2 & 4.39 & 45 \\
\hline $\mathbf{1 0 0} \mathbf{~ n m}$ & 11.36 & 1.065 & 58.0 & 7.02 & 44 \\
\hline $\mathbf{1 8 0} \mathbf{~ n m}$ & 18.38 & 1.082 & 58.5 & 11.63 & 33 \\
\hline $\mathbf{2 5 0} \mathbf{~ n m}$ & 17.97 & 1.060 & 58.4 & 11.13 & 19 \\
\hline
\end{tabular}

${ }^{1}$ Average transmittance for the device without the metallic cathode.

The main difference when decreasing the perovskite thickness is the lower current density that the devices produce, as the FF and $V_{\text {oc }}$ are almost not affected when using active layers thicknesses above $100 \mathrm{~nm}$. Nevertheless, there is an important decrease for the $40 \mathrm{~nm}$ devices, which affects strongly the device performance. The best efficiencies are obtained for $180 \mathrm{~nm}$ and $250 \mathrm{~nm}$ perovskite films, leading to values of PCE close to $12 \%$. Comparing these results with the obtained for the ST cells it is evident the limitation that the ST electrode may has in the current density during the device operation, lowering the resulting FF. Moreover, the device with $180 \mathrm{~nm}$ of active layer shows a high value for PCE and AVT of $33 \%$ without the top electrode. These results suggest that really high efficiencies could be achieved with a proper semitransparent electrode.

\section{Transmittance spectra for optimized device}

The transmittance spectra trough a typical semitransparent solar cell with the best semitransparent electrode $(\mathrm{Au} / \mathrm{LiF})$ and $100 \mathrm{~nm}$ of perovskite thickness is shown in Figure S2.

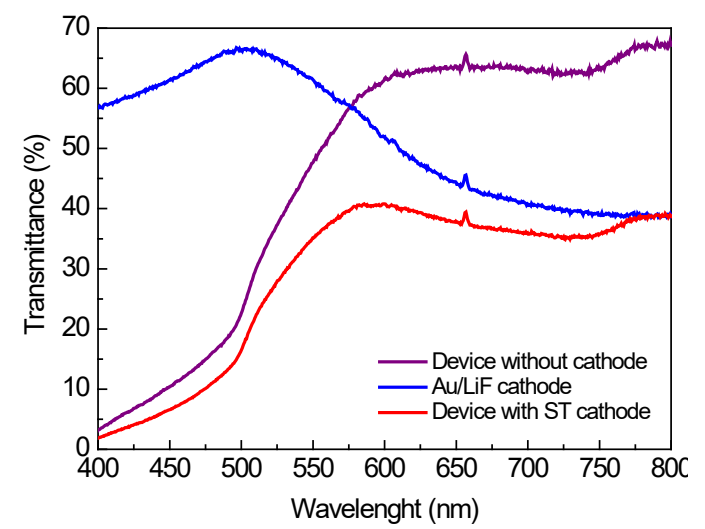

Figure S2. Transmittance spectra for the device without top electrode, the semitransparent (ST) top contact and the completed device with ST top contact using a perovskite layer thickness of $100 \mathrm{~nm}$.

\section{Chromaticity coordinates for the semitransparent devices}

The color calculation of both actual and simulated devices is based on the determination of the CIE 1931 chromaticity coordinates $x$ and $y$. Given the devices transmittance $T(\lambda)$ and taking as reference the daytime $D 65(\lambda)$ standard illuminant, ${ }^{6}$ the $X, Y$ and $Z$ tristimulus values are calculated as follows: ${ }^{7}$ 


$$
\begin{aligned}
X & =\frac{1}{N} \int_{\lambda} \bar{x}(\lambda) T(\lambda) I(\lambda) d \lambda \\
Y & =\frac{1}{N} \int_{\lambda} \bar{y}(\lambda) T(\lambda) I(\lambda) d \lambda \\
Z & =\frac{1}{N} \int_{\lambda} \bar{z}(\lambda) T(\lambda) I(\lambda) d \lambda
\end{aligned}
$$

Where $N=\int_{\lambda} \bar{y}(\lambda) I(\lambda) d \lambda$ and $\bar{x}(\lambda), \bar{y}(\lambda)$ and $\bar{z}(\lambda)$ are the CIE standard observer functions. Finally, the chromaticity coordinates are directly calculated as:

$$
\begin{aligned}
& x=\frac{X}{X+Y+Z} \\
& y=\frac{Y}{X+Y+Z}
\end{aligned}
$$

Figure S3 shows the CIE $(\mathrm{x}, \mathrm{y})$ coordinates calculated for the semitransparent devices using both the transmission spectra of the experimental devices and the predicted ones in the optical modeling.

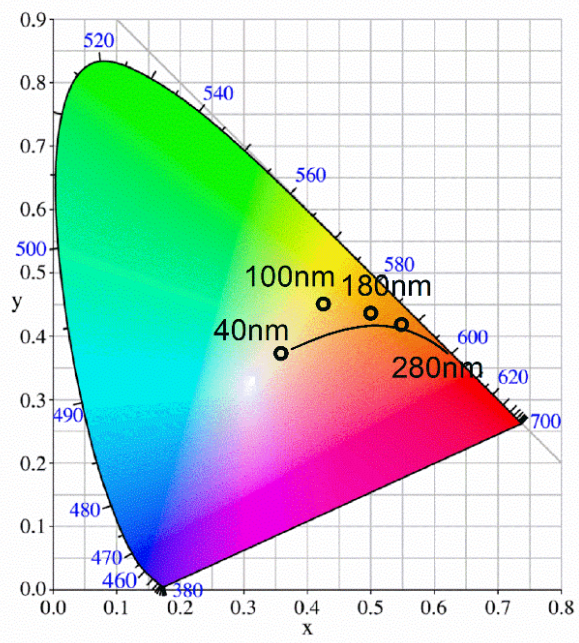

Figure S3. b) CIE 1931 color coordinates calculated using the transmission spectra of the experimental devices (black circles) and the transmission spectra predicted in the optical modelling (solid line).

All devices exhibited a yellowish/brown tonality with considerably good agreement with the optical modelling. The $40 \mathrm{~nm}$ thick perovskite device displayed the most neutral color $(0.36 ; 0.37)$ and future works could be addressed to develop optical strategies to tune such tonalities.

\section{Notes and references}

1. L. Etgar, P. Gao, Z. Xue, Q. Peng, A. K. Chandiran, B. Liu, M. K. Nazeeruddin and M. Grätzel, Journal of the American Chemical Society, 2012, 134, 17396-17399.

2. O. Malinkiewicz, A. Yella, Y.H. Lee, G. Mínguez Espallargas, M. Grätzel, M. K. Nazeeruddin and H. J. Bolink, Nature Photonics, 2014 , 8, 128-132.

3. G. S. Pawley, J. Appl. Cryst., 1981, 14, 357-361.

4. Coelho, A. A. TOPAS-Academic, Version 4.1, 2007, see: http:// www.topas-academic.net.

5. S. Schubert, J. Meiss, L. Müller-Meskamp and K. Leo, Adv. Energy Mater. 2013, 3, 438-443.

6. Commission Internationale De L'eclairaige. (2013).

7. Betancur, R. (2013). Photon control in nano-structured organic photovoltaic materials (Doctoral dissertation, Universitat Politécnica de Catalunya Barcelona). 